\title{
Evidence of Environmental Justice: A Critical Perspective on the Practice of EJ Research and Lessons for Policy Design*
}

[This is an electronic version of an Article published in Social Science Quarterly:

Noonan, Douglas S. 2008. "Evidence of Environmental Justice: A Critical Perspective on the Practice of EJ Research and Lessons for Policy Design.” Social Science Quarterly 89 (5): 1154 - 1174.]

Douglas S. Noonan

Georgia Institute of Technology

* Direct correspondence to: Douglas S. Noonan, School of Public Policy, Georgia Institute of Technology, Atlanta, GA 30332-0345 (Doug.Noonan@gatech.edu). Douglas Noonan will share all coding information and data with those wishing to replicate the study. This material is based upon work supported by the National Science Foundation under Grant No. 0433165. Earlier drafts benefited greatly from Julian Agyeman, Brett Baden, and conference participants at the Association for Public Policy Analysis and Management. 


\section{Evidence of Environmental Justice: A Critical Perspective on the Practice of EJ Research and Lessons for Policy Design}

\section{The EJ literature}

In environmental policy, the disconnect between the pursuit of individual interests and the pursuit of collective goals is paramount. In this sense, the acrimony surrounding many environmental policy debates is both understandable and inevitable. Environmental justice (EJ) is a major theme in environmental and social policy. A debate about the empirical evidence and appropriate policies continues among academics. After scaling this mountain of literature, what are some important lessons to be learned for making EJ policy? From this vantage, this paper critiques the field of EJ research. It also offers some suggestions for more closely linking the EJ research agenda to policy. The conclusion returns to the broad assessment of EJ policy and suggests some future directions for designing policy and framing the discourse.

The background of environmental justice - the EJ movement, research, and related polices - has been rehearsed elsewhere. For useful histories, see Ringquist (2006), Agyeman and Evans (2004), Bowen and Wells (2002), Bowen (2000), Liu (2000). The emphasis here is on the nature of the debate and discussion among academics. In particular, this article limits its attention to the part of the literature concerned with identifying evidence of environmental inequities.

The universal support for the notion of "justice” belies the contentious nature of defining and pursuing it. The search for empirical evidence of environmental injustice (or inequity) has attracted the attention of a wide range of scholars, including those in the fields of sociology, public and environmental health, law, geography, political science, economics, planning, and environmental studies. From such disparate fields, using disparate methods, what constitutes 
evidence of injustice varies widely in the literature. Likewise, the quality of research has ranged widely in the literature (see, e.g., the discussions in Ringquist 2005, Bowen 2000).

The scholarly discourse has addressed several important issues in empirical research. More detailed critiques can be found at Bowen (2000), Mitchell and Walker (2007), and Schweitzer and Stephenson (2007). First and foremost, there are methodological concerns. Liu (2000) categorizes these issues as concerning measurement of impacts, measurement or populations, defining units of analysis, statistical analysis, and modeling spatial and urban systems. Some measures of injustice have been contested (see, e.g., Maantay 2002, Mennis 2002, Jerrett et al. 2001) as inappropriate, especially the proxies used for actual or potential environmental risks or impacts.

There is also debate over the generalizability of research findings. This is especially true for those results derived from case studies or from studies using methods where the sample is selected based on the dependent variable (Ringquist 2006, Ringquist 2005, Bowen and Wells 2002, Bowen 2000). At the heart of much of the methodological debate rests the researcher's choice (often dictated by data availability) of units of analysis. Researchers' choices of spatial scale - both extent and resolution - may not be neutral to the results (see Section 2, below). The difficulties posed for drawing generalizable conclusions when the scale of the observations differs from the scale of analysis or the scale of the phenomenon of interest has long been known as a problem of ecological inference. To parallel the complexities of spatial scale, temporal dimensions of EJ research pose particularly thorny problems. Cross-sectional studies, which note that environmental hazards are disproportionately collocated with certain groups, fail to identify the sequence of events that led to such an equilibrium. Adjudging a particular situation as just or unjust, according to these critics, implies going beyond questions of mere distributional 
equity. Some explanation of how the inequitable circumstances came about seems necessary (Helfand and Peyton 1999, Baden and Coursey 2002).

The bulk of this empirical EJ literature can be characterized by a continued quest to expand the scope of studies, to improve empirical methodologies, and occasionally to dispute the validity or relevance of findings. Most studies advance the field of EJ research by studying a new application (e.g., new risks, pollutants, regions, data) or by employing new methods (e.g., better exposure models, more robust statistical analyses). Rarely, and contentiously, an author more fundamentally questions the EJ research enterprise. Chief among the critiques are Anderton et al. (1994), Hamilton (1995), Straw (1995), Been and Gupta (1997), and Bowen (2000). These studies distinguish themselves by calling into question basic assumptions in the modeling approaches taken in conventional EJ research, suggesting that typical EJ evidence may hardly identify the injustice that EJ advocates lament.

Insofar as academia reflects or supports an environmental justice movement, such critiques remain at the fringe of the discourse. Sometimes, the critics have drawn the ire of other EJ researchers (e.g., Ringquist 2005 and Been 1995 critiquing Anderton et al. 1994, Timney 2002 critiquing Bowen 2000). Yandle and Burton’s (1996) finding no evidence of racial inequities invoked no less than three critiques in this journal. Yet Helfand and Peyton's (1999) challenge, in the same journal three years later, to conduct more than cross-sectional studies with reduced-form models garnered no responses in this journal. ${ }^{1}$ Most empirical EJ studies still adopt cross-sectional approaches without sensitivity to spatial scale problems or temporal dynamics. ${ }^{2}$

That the EJ literature has not yet answered these critiques and substantially advanced in explaining inequities may arise from several influences. Pellow et al. (2001) imply the absence 
of explanatory models in the literature results from the limitations of quantitative methods. Alternatively, the nature of the EJ research enterprise limits the sorts of questions that are of interest (Schweitzer and Stephenson 2007). In the quest to find environmental inequity for some groups, certain comparisons (e.g., overall welfare across groups, preferences across groups) and explanations are often deemed secondary. Moreover, the EJ movement has attracted researchers from many disciplines who may be unaware of important existing literatures and methods.

This mulitidisciplinary research agenda has researchers taking very different approaches to questions of justice. For instance, economists' analytical frameworks often map awkwardly onto the EJ discourse. While advocates press for more equal distribution of a particular environmental harm, economists are given to examining the distribution of welfare and utility rather than a select few contributing elements in isolation. The predominantly static or crosssectional analysis of the research generally fails to incorporate a structural model of what might give rise to such equilibria. As such, many claims of environmental injustice might be seen as no more than lamenting that the group driving into a store's parking lot has more disposable income than the group driving away. Much EJ research offers little rigorous evidence to explain why distributions are as they are. In light of these concerns, economists frequently regard the EJ literature as a source of more heat than light. Notably, not all economists stay on the sidelines (e.g., Hamilton 1995, Baden and Coursey 2002, Earnhart 2004, Gray and Shadbegian 2004). Many in the environmental justice community have also avoided environmental economics. Besides the perception that mainstream economists represent the prevailing power structure responsible for present-day inequities, they have many reasons to steer the political debate away from economics. Economists' insistence on formal modeling often makes the research indigestible, especially to policy advocates. Consumer sovereignty combined with 
preference heterogeneity makes environmental equity a dubious goal to many economists. To them, it is hardly a human right. In addition, many economists' inclination toward efficiency makes them accepting of unequal distributions (due to optimal sorting or economies of scale, for example), often conditional upon some compensation scheme. This compensation might be nonpecuniary, such as investments in other public or environmental goods. When an economist sees a landfill surrounded by poorer residents, he is as likely to see households shrewdly saving on rent as to see households suffering environmental injustice. Yet broaching the possibility of unequal distribution with compensation muddies the simple EJ analysis, which specially privileges inequities in the environmental realm. Section 3 revisits the topic of net impact.

\section{Researchers' Choices and Robustness of Evidence}

The typical review of the empirical EJ literature summarizes the results of dozens or even hundreds of original studies and usually concludes that the evidence (of injustice) is strong although some inconsistencies remain. See Ringquist (2005), Maantay (2002), Bowen and Wells (2002), and Brown (1995) for examples of such literature reviews. In 110 EJ studies reviewed here, only 14 reported no significant evidence of injustice, yet 23 of the remaining 96 reported at least one model with no evidence of injustice. Throughout the research process leading up to these results, researchers (and editors) make many important choices.

Most studies use crude proxies for environmental quality or actual exposure. It is common to use the spatial correlation of an aggregate demographic measure (e.g., percent black, per-capita income) and the presence of one or more regulated facilities as indicative of environmental injustice. Some studies go further in spatially correlating demographic aggregates and some measures of environmental harms coming from within that area. Except for air quality 
studies (24 out of 110 sample studies), only the rare and most thorough studies employ measures of actual environmental quality or risk exposure. Very rarely is the dependent variable a "change in” or rate or trend.

Studies draw their samples using different approaches. Case studies are frequently employed, as are samples that range from a local to a national scope. Within the sample region chosen by the researcher, measuring how demographics differ geographically requires observing demographics at some scale, such as the individual or household, the Census tract, the county, or other scales. Obviously, for studies using aggregated demographics, the researcher's choice of the appropriate scale and zone over which to aggregate warrants special attention. In practice, data limitations push most researchers to use Census-defined areas.

\section{An Example: Scale Choice}

To demonstrate the sensitivity of empirical evidence to researchers’ choices, consider spatial scale. Numerous studies have explicitly acknowledged the potential importance of the choice of scale (see, e.g., Liu 2000, Bowen 2000, Been and Gupta 1997). An overview of the literature helps put scale issues into perspective. In contrast to Fotheringham and Wong’s (1991) pessimism about identifying predictable effects especially for multivariate analyses, many authors in the EJ literature express intuitions and expectations about the effects of spatial resolution choice. Panel A of Table 1 summarizes some of these expectations. Furthermore, several studies have provided some empirical evidence of the effect of resolution choice. Panel B of Table 1 summarizes their findings. In total, while the conventional wisdom may be that effects get stronger as resolution becomes coarser (Panel A), the empirical evidence on the matter is quite mixed (Panel B).

[Table 1 here] 
Baden et al. (2007) demonstrate the sensitivity of EJ research findings to modeling assumptions. Their analysis follows a conventional approach, predicting the cross-sectional distribution of 1,633 sites on the National Priorities List (NPL) of the federal Superfund program. A logit model explains the presence of a high-risk site in a geographic region. The same model is estimated four times, once at each of four scales (i.e., county, zip code, tract, block group) commonly used in EJ research. This same analysis is then repeated separately for California and for LA County subsamples. ${ }^{3}$ Table 2 summarizes their key justice-related results. [Table 2 here]

The results depict an inconsistent story, at best. On the one hand, small scales may show evidence of environmental injustice for blacks depending on the sample. Income injustice is also evident at some resolutions and extents. On the other hand, evidence of both injustice and reverse injustice can be found for income and percent Hispanic, depending on the scale and sample. Even injustice for blacks is not robust across models. What is the EJ policymaker (e.g., court, agency) supposed to do when confronted with these results and lacking guidance on what constitutes valid evidence? The substantive findings themselves cannot provide the answer. Mohai and Saha (2006) offer excellent methodological guidance to avoid bias in the construction of spatial variables. Their guidance does not indicate which scale is ultimately appropriate, however, only how to construct the measures conditional upon a particular scale.

Often in the literature, researchers favor the 'scale appropriate to the impact' (e.g., Liu 2000, Ringuist 2005) with little formal justification. Others seem to favor 'the smallest available scale’ (e.g., Anderton et al. 1994, Maantay 2002), again with little formal justification. Tellingly, in Liu's (2000) book on methods of EJ analysis makes no mention of individuals in the chapter on "Defining Units of Analysis." The appearance that units of analysis are selected 
by EJ researchers arbitrarily or conveniently remains (Baden et al. 2007). More guidance in operationally defining basic concepts in empirical testing for evidence of injustice might follow assertions by policymakers (e.g., legislatures, agencies, courts). While the EPA's Council on Environmental Justice (CEQ 1997) shunned giving specific guidance, it did offer some principles. The CEQ instructs that units of analysis should be chosen "so as to not artificially dilute or inflate the affected minority population” (p.26), although what this entails in practice where "true" measures are typically lacking - is unclear.

In the end, these studies typically reveal whether or not some indicator of environmental conditions (e.g., presence of a hazwaste site) in an area and some demographic measure (e.g., percent black) for that area are correlated among a sample of areas in some region. With potentially many indicators, many areas, and many regions, it is hardly surprising to see such a large literature. Generalizing from even the widest survey of the EJ literature, however, is limited by the nature of the research questions asked in these studies. Rarely do EJ studies examine the distribution of environmental amenities (e.g., aesthetics, parks, wilderness). Rarely do they measure environmental quality actually experienced by individuals. Rarely do they incorporate a temporal dimension. Rarely do they consider geographic areas other than those used by the Census (or derived from those Census units). Rarely do they articulate a formal model (with testable hypotheses) to explain the observed data (thus, the inclusion of some explanatory variables appears to be arbitrary researcher choices). And rarely do they measure overall welfare or quality of life.

\section{Questioning the Research Questions}

\section{Just States or Just Policies?}


Ironically perhaps, the EJ literature devotes much energy to identifying environmental injustice and surprisingly little effort to defining a just equilibrium. Several conceptions are possible. The justice of an equilibrium may depend on the outcome meeting specified conditions. It might also or instead depend on the conditions of the process by which the outcomes are generated. If an EJ policy problem exists insofar as just equilibria are not present, then the conditions that could give rise to such equilibria become of paramount importance to policy design. Yet relatively little attention is paid to how such a just world could actually be constructed - and whether or not such conditions would even be desirable from an individual or a societal standpoint. ${ }^{4}$

Designing a just policy, rather than a just state of the world, may seem far more straightforward and practicable. Yet it is not without serious and possibly insurmountable challenges (Been 1993). Much of this depends, again, on the precise definition of injustice. What are the spatial and temporal dimensions at which injustice can be observed? Which populations are to be treated "fairly," relative to whom, and controlling for what?

\section{Defining Impacts: Environmental Harms with no Compensation?}

Consider in more detail one aspect of defining environmental justice: how environmental quality is to be measured. Most EJ research looks at noxious or toxic facilities (or emissions or risks from those facilities). In the 110 studies sampled, 94 fit this description. These are hardly indices of overall environmental quality, and they purposefully avoid measuring a holistic notion

of quality of life or well-being. ${ }^{5}$ They also may not capture the full impacts. The CEQ (1997) defines "impacts" to include environmental, social, economic, and other effects, yet most studies construe impacts very narrowly. By restricting the analysis to just part of the environmental dimension, the degrees of freedom for policymakers shrink. For instance, designing 
compensation schemes into policies cannot overcome environmental injustice if empirical measures of injustice are so constructed.

As a thought experiment, imagine that communities received compensation for disamenities. Here, they would have little incentive to mobilize under the banner of an EJ movement seeking to equalize environmental quality. Relocating their disamenities would eliminate the compensation. The absence of compensation in the first place motivates communities to demand policy remedies. If least-cost host communities also tend to be minority or low-income, then the mobilizing communities may find something else in common: their disadvantaged status. Yet just because the hosts tend to be disadvantaged does not imply that they host because they are disadvantaged or that they should not host. Recall that the discontent and mobilization was conditional on the lack of compensation, not on disadvantaged status.

Yet there is something more to EJ than fairness achieved via compensation (Been 1993). The appeal to deeper (non-environmental) social justice and human rights concerns marks a significant departure in rhetoric and practice from traditional efforts to use legal and political processes to obtain remedy for uncompensated harms. ${ }^{6}$ Disadvantaged communities can tap into two sources of support: one for their prevailing social condition, and one for their correlated environmental condition.

\section{Causality and Remedying Injustice}

The modal empirical EJ study tests hypotheses about the equity of cross-sectional distribution of environmental conditions across aggregated demographic measures, occasionally controlling for some other variables. The research typically does not ask how these equilibria came about, why they came about, or what the implications are in a more holistic sense. While these questions might be secondary to the limited question of distributional equity, they seem 
important to a judgment of "injustice” (Baden and Coursey 2002) and are crucial to designing policy remedies (Helfand and Peyton 1999, Bowen and Wells 2002). Understanding the forces that give rise to the offending equilibrium seems like essential information to designing a policy to alter it. Prejudiced siting practices suggest one policy remedy. Unequal political activism suggests another. Unequal endowments of income or information suggest others. White flight and exclusionary zoning suggest still others.

Asking these questions opens the door to a deeper analysis. Studying the distribution of harms is decidedly different than studying the distribution of the impacts of decisions, policies, or institutions. The equity of impacts of some policy (whether an overt policy, like a permitting or siting decision, or a more indirect policy, like enabling private land markets) can be assessed once an appropriate measure of impact is determined. While "net impact" might be a useful starting point, nearly all EJ studies reject this measure in favor of something else.

\section{Identifying Counterfactuals}

Given an appropriate notion of impact, measuring it requires a research design capable of identifying the effect of the policy. This analysis requires some knowledge of a counterfactual world. In the absence of that (policy, institution, etc.) which gave rise to the observed equilibrium, we would realize the counterfactual. Depending on the context, the assumptions involved in constructing the counterfactual may be quite contentious. Yet it is difficult to imagine how the impacts of a policy are to be assessed without some idea of a counterfactual. Inferring that an equilibrium is unequal or unjust cannot escape identifying some point of comparison or counterfactual equilibrium.

In practice, EJ research dwells on this question only briefly if ever. In much empirical EJ research, the counterfactual or comparison is often (1) undisclosed, (2) taken as some uniform or 
random distribution of environmental quality, or (3) made using the reference group (e.g., white neighborhoods). In the first case, little can be said of the validity of the inference that a policy or system is unjust because the alternative world is unknown. In the second case, any observed inequity is prima facie evidence of an unjust policy or system. Such a counterfactual may be more useful as a thought experiment than as a feasible alternative world. ${ }^{7}$ Yet it may be the most common counterfactual employed in EJ research. The third case presents a more complex situation. The current policy or system gives rise to the observed (in)equity, whereas the alternative policy or system would, apparently, give rise to the same impacts for all groups as the reference group currently enjoys. For instance, all black neighborhoods would have as few landfills as the white neighborhoods. Such a counterfactual assumes fewer total landfills. Thus, the comparison involves an alternative distribution of disamenities and an alternative quantity of them. Regardless, the policy or system that gives rise to the counterfactual may be difficult to imagine and is generally not specified in EJ analyses.

Unfortunately, the counterfactual is far more important than most EJ research lets on. Studies purporting to show disparate impact often merely identify disproportionate distribution. The injustice of the observed level of equity or inequity depends on the alternative world that the researcher or advocate imagines. If the counterfactual was equitable, any observed disproportionate distribution would imply an inequitable policy or other change. If the counterfactual was inequitable, however, a policy or other change could improve, worsen, or maintain conditions. Inequitable counterfactual distributions might rightly belong in EJ analyses. In the absence of a policy or decision, harms may not be equitably distributed. Baden and Coursey (2002) offer an intriguing example of discriminatory policies - redlining in Chicago during the 1960s - inadvertently protecting certain subpopulations from exposure to hazwaste 
sites. The currently observed equity belies the discriminatory policy and possibly inequitable counterfactual. Even as observed equity may be evidence of an unjust policy, observed inequity may be evidence of just policies. Much hinges on the specified counterfactual.

\section{Back to the Nature of EJ}

Yet surprisingly little effort has gone towards answering those questions (why is the equilibrium as it is? how is this more or less just than some counterfactual?). Certainly one reason for this is that such research is far more difficult than static equity studies. Perhaps another major reason for this disinterest can be traced back to the nature of the EJ movement.

Environmental justice is steeped in notions of social equity, of value judgments, and of a social policy that ostensibly favors the vulnerable and the disadvantaged. The environmental justice discourse is difficult to disentangle from a political agenda. Even if ambiguous, the premise for and conduct of the research is grounded in a political discourse (Williams 1999, Kurtz 2003). Showing conditions to be inequitable gives political ammunition to EJ advocates. How they are able to use that evidence, however, depends on the situation and prevailing policies. See Bowen (2000) for a discussion of advocates' use of scholarly research.

Scientific certainty and an understanding of causal mechanisms is often a secondary consideration, at most, in a policy setting. Causal evidence can be unnecessary or even undesirable in a political context. Such information might undermine the legitimacy of the EJ movement's policy aims. ${ }^{8}$ For example, suppose that the inequity was shown to arise from lack of collective action on the part of minority communities (see, e.g., Hamilton 1995) rather than unequal endowments of wealth. Advocates seeking financial compensation rather than additional political empowerment might view the additional research findings less than favorably. In addition, findings that suggest that the inequity arose due to minorities 
disproportionately seeking out hazardous sites may weaken the advocate’s position.

Accordingly, the limitations of the body of EJ research can be at least partially linked to its limited use in the political arena.

\section{Some Lessons from the Empirical Literature}

It has been argued that the politics of EJ limit the useful or relevant empirical research, placing considerable emphasis on studies of cross-sectional distribution of environmental disamenities. Such research is sufficient evidence to support EJ advocacy. Relatively little interest has been paid to actually evaluating the equity of impacts of environmental policies. The net impacts of these policies or systems - where the observed outcomes of a policy are compared to the outcomes under some counterfactual scenario - are virtually unknown to the EJ literature.

With this rather bleak diagnosis of the literature, what can be said of its implications for design of EJ policy? First, and most pragmatically, it should be noted that clear definitions of justice and injustice are crucial. The conditions that must be satisfied for something to be judged “just” or "unjust” should be thought out well in advance and clearly operationalized for empirical observations. An explicit statement on valid methods of data analysis may also be warranted. Although it appears cumbersome from a policymaking standpoint, sufficient guidance must be present in the EJ policy to direct an empirical researcher seeking to observe something so essential as the mere existence of the problem. How can this be done? Are case studies valid evidence, or does the policy refer only to broad patterns in society rather than idiosyncratic injustice? Is inequity observable using aggregate data (e.g., Census tracts), or must it hinge on observations of individuals? What methods of spatial aggregation are valid for drawing inferences about the existence of injustice? What are valid control variables? 
Perhaps it is unfortunate, but EJ policy that offers no guidance on these sorts of questions will do little to improve current policy. Today's ambiguity and acrimony will likely persist. And, like many other areas of environmental policy (e.g., air quality, multiple-use of public lands), the ambiguity may enable the implementers of the policy to achieve a working definition that adequately mollifies all parties so as to forestall reform by the legislature.

Recall the demonstration in Table 2. It seems that Table 2 has evidence to support any advocate's position, regardless of what that position is! EJ supporters may like small scales for their analysis, while their opponents might prefer large units for their's. Obviously, the evidence can be insufficient to resolve the debate. For EJ research to have significance or consistency beyond ad hoc declarations of what constitutes valid evidence, some clearly articulated principles need to be advanced to guide decision-makers facing real-world complexities and evidence.

Empirical evidence on Superfund and its distributional issues typifies the complexities in drawing inferences about environmental injustices and in designing policy remedies. For simplicity, assume for now that Census block groups are the appropriate unit of analysis. Closely replicating the Baden et al. (2007) analysis appearing in Table 2, Table 3 shows how evidence of distributional equity varies depending on the "control group." In other words, what may seem just by one counterfactual seems unjust by another when those control variables are not distributed independently. That control variables help define the counterfactual and thus the meaning of "injustice" can make the researcher’s choice pivotal.

Empirical evidence on Superfund and its distributional issues typifies the complexities in drawing inferences about environmental injustices and in designing policy remedies. Baden et al. (2007) remind us of how critical spatial scale and scope are. Yet assessing distributional 
equity hinges on how "justice" is defined in other dimensions as well. Table 3 extends the previous analysis of Superfund site distribution to demonstrate how these definitional choices are both pivotal and contentious. ${ }^{9}$ The first five models show how different control variables greatly alter the apparent inequity in distribution of NPL sites. The second four models show how different definitions of which units are impacted also seriously affect the evidence of inequity. The last two models, discussed later, modify the definition of impact again.

Changing the control variables entails more than just changing the significance and sign of the results. It implies different concepts of injustice and different criteria for evidence. Model 1 shows that block groups with greater shares of white residents and with lower incomes are more likely to host an NPL site. Yet, once population density, population, and presence in an MSA are controlled for, this evidence of inequity partly reverses itself. Model 2 shows NPL sites to be more common in minority and wealthy areas (although income effects are insignificant). Similar results are found in Model 4, which adds in MSA-level fixed effects. Model 3, close to the Baden et al. (2007) specification, adds controls for state-level fixed effects. And, finally in Model 5, with both MSA- and state-level controls, the results show NPL sites tend to be found in poor, minority areas. Which specification is appropriate depends on the definition of justice. The first model clearly indicates that areas with greater shares of white residents, not minorities, are more likely to host NPL sites. The disproportionate exposure to NPL sites for minorities depends on controlling for population density. Arguably, whites are disproportionately exposed to NPL sites, although at any given population density they appear under-exposed to NPL sites. Likewise, the strength of the correlation between income and NPL sites depends on the control variables.

Conceptually, whether inequity is unconditional or conditional has great consequence for 
research design and for policy design. Perhaps any inequity - unconditional and conditional - is unjust and worthy of remedy. Most EJ evidence arises from reduced-form models (Helfand and Peyton 1999), often with little justification for why the evidence of injustice ought to be conditional. Given the complexity of the distributions and the enormous array of possible controls, researchers might not need to look far to find a significant correlation between race or income and exposure conditional on something. The percent white of areas within 1 mile of NPL sites, based on the areal concentration method described by Mohai and Saha (2006), was $61.2 \%$, compared to the national average of $70.1 \%$ for block groups in 2000. (Median household incomes near sites are virtually identical to national averages.) Yet Table 3 shows how the apparent disproportionate exposure can change radically depending on the controls.

The conditionality of inequity is no less salient to designing a policy to tackle inequitable exposure to NPL sites. Suppose that a just Superfund policy ensures that exposure to NPL sites was somehow proportionate to race. To achieve the policy aim, given existing distributions of eligible sites and populations, a policymaker would need to carefully select sites for the NPL. Random selection might fail if eligible sites were not distributed independently from race. Alternatively, a policy that aims for proportionate exposure conditional upon something (e.g., preexisting eligible sites, the state or the MSA in question) targets a very different objective. Meeting the conditional objective may not satisfy the unconditional objective, and vice versa.

Evidence of injustice is also highly sensitive to the definition of which units are affected by the disamenity. The NPL results in Table 3 demonstrate this. The model replicating the strongest evidence of injustice from Baden et al. (2007), Model 3, gives inconsistent results when the choice of impacted units changes. When hosts are block groups with NPL sites (Model 3) or are block groups whose centers are within one mile of NPL sites (Model 6), conditions look 
worse for nonwhites and the poor. The same holds when hosts are defined as block groups with most of their area contained in a one-mile radius of the site (Model 8). Yet expanding the radius to six miles, the upper limit of NPL sites’ observed impacts on property values (Noonan et al. 2007), makes the income effect vanish (Model 9) or even reverse signs (Model 7). Some caution is advised in drawing strong conclusions given the complexity of the circumstances, possibility of data mining, and absence of clear a priori guidelines for policy relevant evidence.

[Insert Table 3 here.]

Secondly, clarity is needed on the sorts of impacts that are relevant for the determination of injustice. This invites questions about causation and chronology, about racist intent or incidental byproducts of other processes. Researchers frequently invoke EJ concerns when environmental conditions are distributed unequally, whatever the cause. The bulk of the EJ literature offers evidence on the inequity of conditions. It is relatively silent on evidence of inequitable impacts of decisions, policies, institutions, etc. Some see EJ policy as equalizing conditions, regardless of their cause. To others, EJ policy aims to prevent or correct discriminatory impacts of decisions or processes. Unambiguous EJ policy might clarify the role of "impact" and help researchers and advocates separate evidence of inequitable states from evidence of inequitable policies.

To continue the NPL example, consider a model of EPA's decisions to delete certain sites from the NPL during the 1990s. Like before, logit models can explain the deletions using demographics (circa 1990) and state- and MSA-specific fixed effects. Following Mohai and Saha's (2006) suggestion, host block groups are those with over half of their area within a 1- or 6-mile radius of a NPL. Some block groups that hosted in 1990 enjoyed deletions during the 1990s (8.1\% for the 1-mile buffer). The results in Table 3 show that among hosts of NPL sites, 
those neighborhoods that were poorer and more minority in 1990 were more likely to have their site deleted from NPL - the final stage in Superfund clean-up. The results for race are significant for a 6-mile radius (Model 11) but not for 1 mile (Model 10). There may be many reasons for this disproportionate impact on poor and minority areas, such as nonrandom distribution of initial site quality, remediation efforts, or clean-up standards. Such an investigation is beyond the scope of the present paper. Instead, it suffices to emphasize here that injustice in conditions (Models 8 -9) may not be represented in changes (Models $10-11$ ). By shifting the focus from the distribution of hazardous sites to the distribution of their clean-ups under the Superfund program, a clearer link between the policy implementation and its impacts is drawn. Starting in 1990 with an inventory of sites on the NPL and a distribution of the population, the EPA managed to delete Superfund sites that tended to be in the more disadvantaged areas. The cross-sectional models cannot resolve the identification problem, where subpopulations may attract sites just as they are attracted to sites. The deletion models, however, overcome this by using 1990 demographics, which are not affected by subsequent clean-ups. While hardly definitive evidence of discrimination in implementation of the policy, these results offer a much stronger connection between policy choices and affected populations than the other models in Table 3, typical of the EJ literature, which show only how listed sites and populations collocate.

A third implication of the empirical EJ literature for policy design is that a critical distinction can be made between equitable outcomes and equitable processes. This time-worn distinction in equity discussions remains central to the politics of EJ and the nature of empirical research. The relevant data tend to describe outcomes, and federal policies to produce more information (arising partly in response to the EJ movement) tend to make information available 
on outcomes rather than processes. In future policies (environmental and otherwise), policymakers would do well to explicitly consider both notions of environmental justice.

Fourth, policy should articulate the relevance of net impacts of policies and whether environmental impacts can be considered piecemeal or must be holistic. The question of whether compensatory gains in other dimensions are relevant in assessing environmental inequities is directly relevant to designing policies to remedy environmental insults. Even if EJ researchers have paid inconsistent or minimal attention to this matter, other changes that coincide with environmental impacts are of pragmatic interest to residents, courts, policymakers, and others. These gains (or losses!) can take many forms. They might be environmental (ample greenery in exchange for high volatile organic compound emissions) or nonenvironmental (more jobs in exchange for industrial sitings), private (lower rent for more disamenities) or public (funding for public schools in exchange for a permit to operate a landfill). EJ policy design could specify the extent to which net impacts matter or which compensations are relevant. Insofar as such decisions and "bounding" of the EJ problem are contentious, it becomes all the more important for such decisions to be made in a transparent and democratic forum rather than by technocrats or academics.

For hazardous sites, their siting and their remediation are often expected to affect local quality of life as well as property values. Risks posed by Superfund sites are often associated with discounted housing. Conversely, after cleaning up the site, rents are often expected to rise to bring the housing market into equilibrium. Gentrification and pricing out poor residents is often a concern with brownfield remediation. The national sample of NPL sites offers some evidence of this. Block groups with NPL sites in 1990 had lower property values than those without, although low land pries can be a cause or an effect of siting. Using the areal 
apportionment method, median housing values within one mile of NPL sites that were deleted during the 1990 s appreciated by $40.1 \%$ during that timespan. This exceeds the comparable rate within one mile of all NPL sites circa 1990 (31.2\%) and the population-weighted national average for block groups (34.2\%). While the evidence elsewhere is mixed on whether residents nearby NPL sites enjoy discounts (Noonan et al. 2007), impacts on local prices can have important justice implications. If price effects of exposure to these harms are insignificant, then it suggests that local quality of life might not be noticeably affected. Conversely, if the price effects are significant, then perhaps those effects are a relevant part of the impacts.

Finally, recent research suggests that there may be good reason to be concerned about the effects of changes in environmental quality on migration. Remediating Superfund sites tends to have pronounced effects on the demographic composition of nearby neighborhoods and on property prices (Noonan et al. 2007, Cameron and McConnaha 2006). Changes in air quality should also affect migration, even within the same airshed, in ways highly correlated with income (Banzhaf and Walsh 2006, Sieg et al. 2004). The dynamic systems that produce the distributions of people and environment that we see are complex indeed. Careful modeling of these systems may reveal unexpected or unanticipated implications for equity. For instance, remediating brownfields in ghettos may appear to bring aid to disadvantaged communities, but might induce gentrification where incoming groups enjoy the bulk of the remediation's benefits. Design of an implementable EJ policy based on direct evidence of injustice should consider these general equilibrium issues.

\section{A Bold Recommendation}

An alternative approach to EJ policy is to abandon it. Such a recommendation is not to 
suggest that social equity and environmental equity are not both laudable goals. Rather, the recommendation is based on the idea that equity (or, at least, distributional implications) is typically central to concerns of policymakers that branding it “environmental justice” and taking it outside of the core of all policy considerations seems inconsistent and distracting to good policy. Agyeman and Evans (2004) argue for the inseparability of EJ and sustainability, while Keohane et al. (1998) explain the inextricable link between distributional effects and efficiency of environmental regulation. Equity is already central to most policy decisions along with other concerns. $^{10}$

Nonetheless, environmental equity garners much special attention. At least three nonexclusive explanations for this special attention come to mind:

a. Inadequate institutions exist for compensating individuals or communities for environmental harms.

b. Spatial clustering by demographics (especially income) tends to correlate with environmental quality.

c. Redistributive politics has moved to a new frontier, moving beyond traditional policies that merely promote social equality to promoting environmental equity. The first two concerns involve defining and measuring impacts and various spatial processes, already discussed at length. The third point casts EJ as another forum for using state power to redistribute resources. More specifically, it views EJ advocates as using politics to redistribute resources couched now in environmental rhetoric (and via environmental policies). Unlike traditional income redistribution policies, however, EJ policies crafted to promote environmental equity may be greatly complicated by the heterogeneity of tastes for environmental goods (unlike income) and perhaps the relative ease with which individuals can switch their environments. 
These different issues all suggest different directions for EJ policy. To some observers at least, the injustice of (a) seems more clear than in (b). The injustice in (c) is quite contested. A new formulation of environmental justice might start with these three points to craft a policy framework.

- The first principle would be to improve institutions so that individuals or communities are compensated for enduring environmental harms. ${ }^{11}$ This means improving land markets, improving property rights and enforcing environmental tort claims, improving political institutions that allocate environmental harms so that hosts receive appropriate compensation.

- The second principle would be to promote additional research into the systems and forces that dictate the location of individuals and communities and environmental amenities. Agencies and policymakers should be directed to prospectively investigate the equity of the effects of their policies (and possibly the equity of their processes).

- The third principle would be to either make explicit the transfer of resources from one group to another (taking place via an environmental policy) or simply avoid it as a matter of environmental policy by leaving redistribution to the broader realm of social policy. This approach borrows from first principles of economics, which might see the rent-seeking among EJ advocates as transaction costs and social waste. Ideally, design the policy to simply transfer the wealth according to some social choice mechanism. The notion of “environmental justice communities” may already track along this line. Or, given the other priorities and specialties of environmental agencies and policymakers, perhaps redistributive policies should be consolidated into another policy area. 


\section{References:}

Agyeman, Julian, and Robert Evans. 2004. ““Just Sustainability’: The Emerging Discourse of Environmental Justice in Britain?” The Geographical Journal 170(2): 155-64.

Anderton, Douglas L., A. B. Anderson, P. H. Rossi, J. M. Oakes, M. R. Fraser. 1994. “Environmental Equity: The Demographics of Dumping.” Demography 31(2): 229-48.

Baden, Brett M., and Don Coursey. 2002. “The Locality of Waste within the City of Chicago: A Demographic, Social, and Economic Analysis.” Resource and Energy Economics 24: 5393.

Baden, Brett M., Douglas S. Noonan, and Rama Mohana Turaga. 2007. "Scales of Justice: Is there a Geographic Bias in Environmental Equity Analysis?” Journal of Environmental Planning and Management 50(2): 163-85.

Banzhaf, H. Spencer and Randall P. Walsh. 2006. “Do People Vote with their Feet? An Empirical Test of Environmental Gentrification.” Resources for the Future Discussion Paper 06-10, Feb 2006.

Been, Vicki. 1993. "What's Fairness Got to Do with It? Environmental Justice and the Siting of Locally Undesirable Land Uses.” Cornell Law Review 78(6): 1001-85.

Been, Vicki. 1995. “Analyzing Evidence of Environmental Justice.” Journal of Land Use and Environmental Law 11: 1-36

Been, Vicki and Francis Gupta. 1997. "Coming to the Nuisance or Going to the Barrios? A Longitudinal Analysis of Environmental Justice Claims.” Ecology Law Quarterly 24:1-56

Bowen, William M. 2000. Environmental Justice Through Research-Based Decision-Making. New York: Garland Publishers, Inc. 
Bowen, William M. and Michael V. Wells. 2002. "The Politics and Reality of Environmental Justice: A History and Considerations for Public Administrators and Policy Makers,” Public Administration Review 62(6): 688-98.

Brown, Phil. 1995. "Race, Class, and Environmental Health: A Review and Systemization of the Literature.” Environmental Research 69: 15-30.

Cameron, Trudy Ann and Ian McConnaha. 2006. "Evidence of Environmental Migration.” Land Economics 82(2): 273-90.

Council on Environmental Quality. 1997. Environmental Justice: Guidance under the National Environmental Policy Act. Washington DC: Executive Office of the President.

Cutter, S. L., Holm, D., \& Clark, L. 1996. “The Role of Geographic Scale in Monitoring Environmental Justice.” Risk Analysis 16(4): 517-26.

Dolinoy, Dana C. and Lynn Miranda. 2004. “GIS Modeling of Air Toxics Releases from TRIReporting and Non-TRI-Reporting Facilities: Impacts for Environmental Justice.” Environmental Health Perspectives 112(17): 1717-24.

Earnhart, Dietrich. 2004. “The Effects of Community Characteristics on Polluter Compliance Levels.” Land Economics 80(3): 408-32.

Fotheringham, A. S., \& Wong, D.W.S. 1991. “The Modifiable Areal Unit Problem in Multivariate Statistical Analysis.” Environment and Planning A 23: 1025-44.

Glickman, Theodore S. 1994. "Measuring Environmental Equity with Geographic Information Systems.” Renewable Resources Journal 12(3): 17-21.

Glickman, Theodore S. 2004. "Evaluating Environmental Equity in Allegheny County.” (New York: Program for the Human Environment, Rockefeller University). Available: http://phe.rockefeller.edu/comm_risk/commrsk3.html [last accessed 14 January 2006]. 
Gray, Wayne B. and Ronald J. Shadbegian. 2004. “'Optimal' Pollution Abatement—Whose Benefits Matter, and How Much?” Journal of Environmental Economics and Management 47(3): 510-34.

Hamilton, James T. 1995. “Testing for Environmental Racism: Prejudice, Politics, Political Power?” Journal of Policy Analysis and Management 14(1): 107-32.

Helfand, Gloria E. and L. James Petyon. 1999. “A Conceptual Model of Environmental Justice.” Social Science Quarterly 81(1): 68-83.

Hockman E. M. \& Morris, C.M. 1998. “Progress towards Environmental Justice: A Five-Year Perspective of Toxicity, Race, and Poverty in Michigan, 1990-1995.” Journal of Environmental Planning and Management 41(2): 157-76.

Jerrett, Michael, R. T. Burnett, P. Kanaraglou, J. Eyles, N. Finkelstein, C. Giovis, et al. 2001. “A GIS-Environmental Justice Analysis of Particulate Air Pollution in Hamilton, Canada.” Environment and Planning A 33: 955-73.

Keohane, Nathaniel O., Robert N. Stavins, and R. L. Revesz. 1998. “The Choice of Regulatory Instruments in Environmental Policy.” Harvard Environmental Law Review 22(2): 31367.

Kurtz, Hilda E. 2003. "Scale Frames and Counter-Scale Frames: Constructing the Problem of Environmental Injustice.” Political Geography 22: 887-916.

Liu, Feng. 2000. Environmental Justice Analysis: Theories, Methods, and Practice. Boca Raton, FL: Lewis Publishers.

Maantay, Juliana. 2002.” Mapping Environmental Injustices: Pitfalls and Potential of Geographic Information Systems in Assessing Environmental Health and Equity.” Environmental Health Perspectives 110(2): 161-71. 
Mennis, Jeremy. 2002. ”Using Geographic Information Systems to Create and Analyze Statistical Surfaces of Population and Risk for Environmental Justice Analysis.” Social Science Quarterly 83(1): 281-97.

Mitchell, Gordon and Gordon P. Walker. 2007. "Methodological Issues in the Assessment of Environmental Equity and Environmental Justice” in Sustainable Development: The Environmental Evaluation Methods. E F Spon.

Mohai, Paul, and Robin Saha. 2006. "Reassessing Racial and Socioeconomic Disparities in Environmental Justice Research.” Demography 43(2): 383-99.

Noonan, Douglas S., Douglas J. Krupka, and Brett M. Baden. 2007. “Neighborhood Dynamics and Price Effects of Superfund Site Clean-up.” Journal of Regional Science 47(4): 66592.

Pellow, David N., Adam Weinberg, and Allan Schnaiberg. 2002. “The Environmental Justice Movement: Equitable Allocation of the Costs and Benefits of Environmental Management Outcomes.” Social Justice Research 14(4): 423-39.

Ringquist, Evan J. 2005. “Assessing Evidence of Environmental Inequities: A Meta-Analysis.” Journal of Policy Analysis and Management 24(2): 223-47.

Ringquist, Evan J. 2006. “Environmental Justice: Normative Concerns, Empirical Evidence, and Government Action” in Vig, Norman and Kraft, Michael, eds. Environmental Policy: New Directions for the $21^{\text {st }}$ Century, Sixth edition. Washington, DC: CQ Press.

Schweitzer, Lisa and Max Stephenson Jr. 2007. “Right Answers, Wrong Questions:

Environmental Justice as Urban Research.” Urban Studies 44(2): 319-337. 
Sheppard, Eric, Helga Leitner, Robert B. McMaster, and Hongguo Tian. 1999. “GIS-Based Measures of Environmental Equity: Exploring their Sensitivity and Significance.” Journal of Exposure Analysis and Environmental Epidemiology 9: 18-28.

Sieg, Holger, V. Kerry Smith, H. S. Banzhaf, and R. Walsh. 2004. “Estimating the General Equilibrium Benefits of Large Changes in Spatially Delineated Public Goods.” International Economic Review 45(4):1047-77.

Straw, Lawrence J. Jr. 1995. “Environmental Justice: Racial Gerrymandering for Environmental Siting Decisions.” Virginia Environmental Law Journal 14: 665-85.

Sui, Daniel. 1999. “GIS, Environmental Equity, and the Modifiable Areal Unit Problem (MAUP)” in Massimo Craglia and Harlan Onsrud, eds., Geographic Information Research: Transatlantic Perspectives (London: Taylor and Francis).

Taquino, Michael, Domenico Parisi, and Duane A. Gill. 2002. "Units of Analysis and the Environmental Justice Hypothesis: The Case of Industrial Hog Farms.” Social Science Quarterly 83(1): 298-316.

Timney, Mary M. 2002. “Coming to the Nuisance or Going to the Barrios? A Longitudinal Analysis of Environmental Justice Claims.” Public Administration Review 62(4):506-8

Viscusi, W. Kip, and James T. Hamilton. 1999. “Are Risk Regulators Rational? Evidence from Hazardous Waste Cleanup Decisions.” American Economic Review 89(4): 1010-27.

Williams, Robert W. 1999. "Environmental Injustice in America and Its Politics of Scale.” Political Geography 18: 49-73.

Yandle, Tracy and Dudley Burton. 1996. “Reexamining Environmental Justice: A Statistical Analysis of Hazardous Waste Landfill Siting Patterns in Metropolitan Texas.” Social Science Quarterly 77(3): 477-92. 
Table 1: Effects of Scale, Identified from Intuition, Theory, or Empirical Analysis

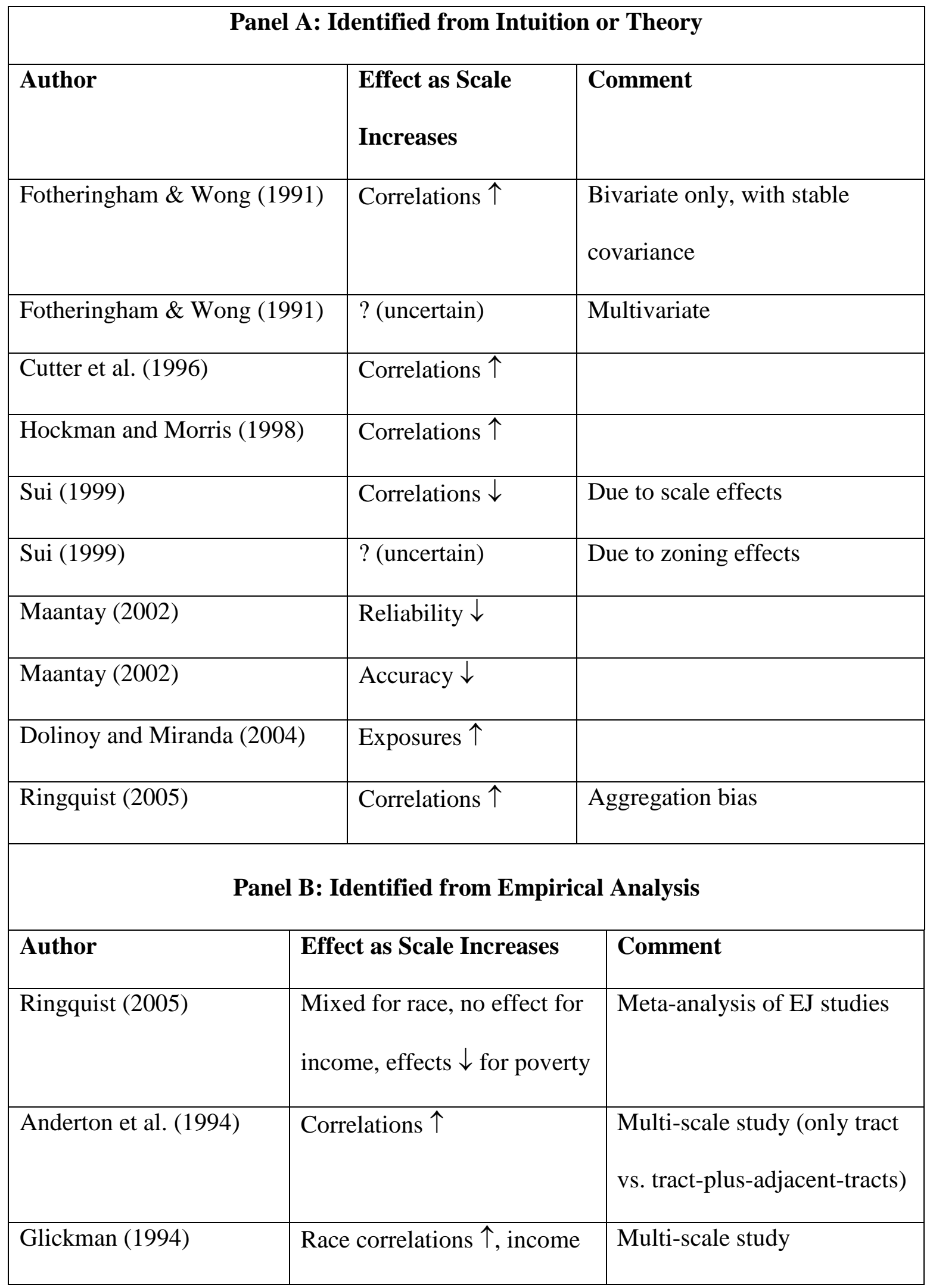




\begin{tabular}{|l|l|l|}
\hline & correlations $\downarrow$ & \\
\hline Cutter et al. (1996) & Correlations $\uparrow$ & Multi-scale study \\
\hline Sui (1999) & $\begin{array}{l}\text { Race correlations } \uparrow \text {, income } \\
\text { correlations } \downarrow\end{array}$ & Multi-scale study \\
\hline Sheppard et al. (1999) & Income correlations $\uparrow$ & Multi-scale study \\
\hline Taquino et al. (2002) & $\begin{array}{l}\text { Income correlations } \uparrow, \text { no } \\
\text { effect for race }\end{array}$ & Multi-scale study \\
\hline Dolinoy and Miranda & Mixed for income, race & Multi-scale study \\
(2004) & correlations $\downarrow$ & \\
\hline Glickman (2004) & Race correlations $\uparrow$, income & Multi-scale study \\
& correlations $\uparrow$ & Mixed; generally race and \\
income correlations $\downarrow$ & Multi-scale, multi-scope \\
\hline Baden et al. (2007) & study \\
\hline
\end{tabular}


Table 2: Summary EJ Results from Logit Analyses of NPL Siting

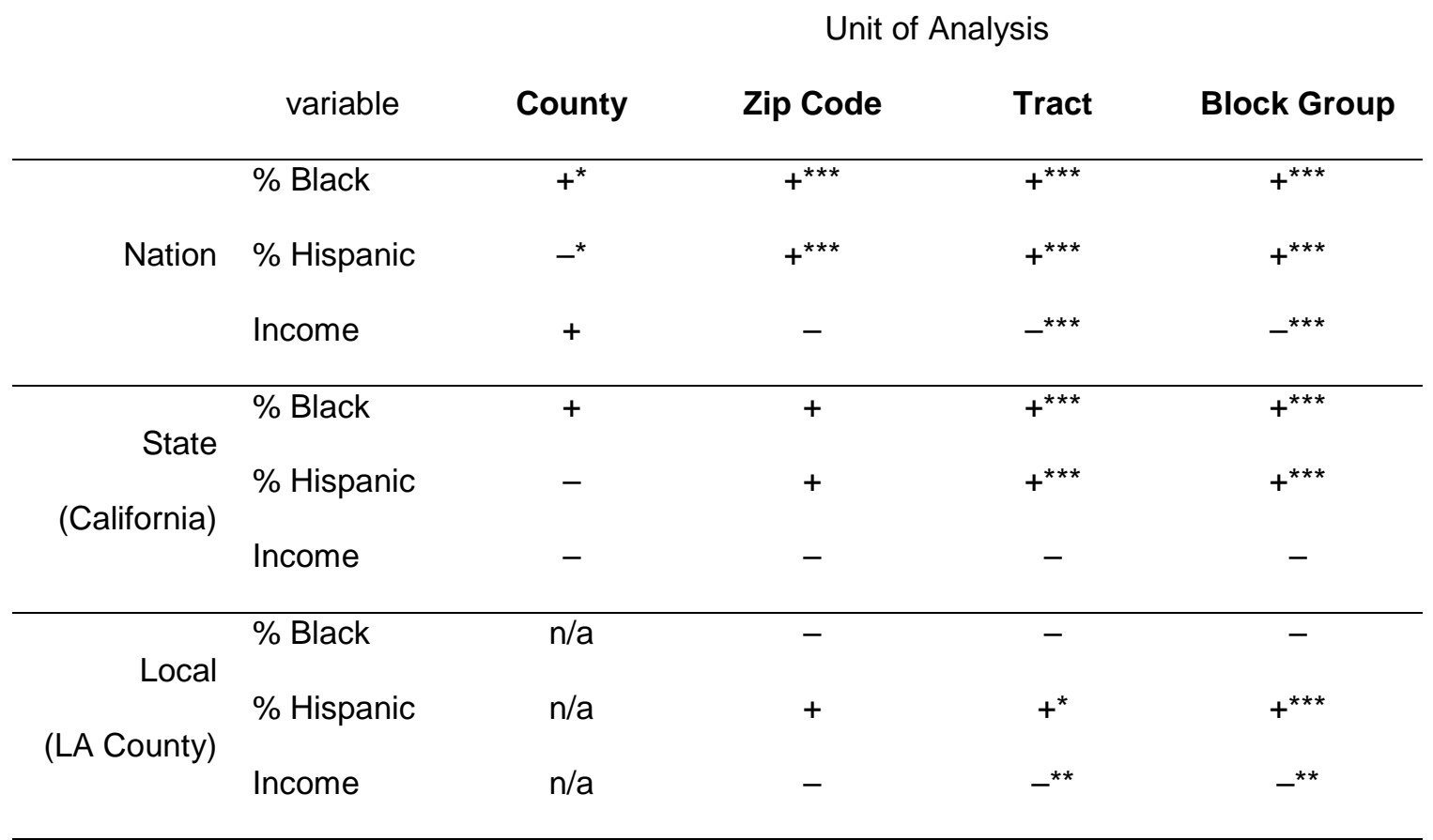

Dependent variable: an NPL site located in the area.

+ positive relationship; - negative relationship

* significant at 10\%; ${ }^{* *}$ significant at $5 \%$; ${ }^{* *}$ significant at $1 \%$

Source: Baden et al., 2007. 
Table 3: Summary Results for Logit Regressions for NPL sites

\begin{tabular}{|c|c|c|c|c|c|}
\hline model & dependent variable & $\begin{array}{c}\text { \% White } \\
\text { coeff. }\end{array}$ & $\begin{array}{l}\text { Income } \\
\text { coeff. }\end{array}$ & controls included & $\mathbf{N}$ \\
\hline 1. & in BG & $0.8934^{* * *}$ & $-0.0022^{*}$ & & 205633 \\
\hline 2. & in BG & $-0.6280^{* * *}$ & 0.0016 & density, population, MSAdum & 205625 \\
\hline 3. & in BG & $-1.1691^{* * * *}$ & $-0.0079^{* * *}$ & $\begin{array}{l}\text { density, population, } \\
\text { MSAdum, State FE }\end{array}$ & 205625 \\
\hline 4. & in BG & $-0.8129^{* * * *}$ & 0.0005 & density, population, MSA FE & 187705 \\
\hline 5. & in $B G$ & $-1.1132^{* * *}$ & $-0.0093^{* * *}$ & $\begin{array}{l}\text { density, population, State FE, } \\
\text { MSA FE }\end{array}$ & 187705 \\
\hline 6. & BG within 1 mi. & $-0.6600^{* * * *}$ & $-0.0072^{* * *}$ & $\begin{array}{l}\text { density, population, } \\
\text { MSAdum, State FE }\end{array}$ & 204582 \\
\hline 7. & BG within 6 mi. & $-1.3695^{* * *}$ & $0.0039^{* * *}$ & $\begin{array}{l}\text { density, population, } \\
\text { MSAdum, State FE }\end{array}$ & 205625 \\
\hline 8. & $\begin{array}{l}50 \% \text { of BG area within } \\
1 \mathrm{mi} \text {. }\end{array}$ & $-0.6650^{* * *}$ & $-0.0079^{* * *}$ & $\begin{array}{l}\text { density, population, } \\
\text { MSAdum, State FE }\end{array}$ & 204582 \\
\hline 9. & $\begin{array}{l}50 \% \text { of BG area within } \\
6 \mathrm{mi} \text {. }\end{array}$ & $-1.0865^{* * *}$ & -0.0000 & $\begin{array}{l}\text { density, population, } \\
\text { MSAdum, State FE }\end{array}$ & 205625 \\
\hline 10. & $\begin{array}{l}50 \% \text { of BG area within } \\
1 \text { mi. of deletion }\end{array}$ & -0.3787 & $-0.0125^{* * *}$ & $\begin{array}{l}\text { density in 1990, population in } \\
\text { 1990, MSAdum, State FE }\end{array}$ & 1902 \\
\hline 11. & $\begin{array}{l}50 \% \text { of BG area within } \\
6 \text { mi. of deletion }\end{array}$ & $-0.4565^{* * *}$ & $-0.0169^{* * *}$ & $\begin{array}{l}\text { density in 1990, population in } \\
\text { 1990, MSAdum, State FE }\end{array}$ & 31371 \\
\hline
\end{tabular}

*, **, *** indicate $\mathrm{p}^{>} .1, \mathrm{p}^{>} .05, \mathrm{p}^{>} .01$ levels, respectively. 


\section{Notes:}

1 No articles in Social Sciences Quarterly have cited Helfand and Peyton (1999). Of 16 subsequent empirical EJ papers in this journal, all estimate reduced-form equations that Helfand and Peyton argue cannot demonstrate causality in complex systems. The inability to make causal claims is only explicit in several of these papers.

2 A sample of 110 quantitative EJ, including many of the most-cited studies according to the ISI Web of Science Social Science Index, was taken from Baden et al. (1997). Of their 110 studies, only 19 presented results at multiple scales, another 18 presented dynamic analyses, and just one did both.

3 The logit model uses as control variables: a dummy for whether the observation is in an MSA; the observation's population, population density, and percent urban population; and the observations' percent employed in manufacturing and percent unemployment. All demographic data are from the 2000 Census.

4 A world of no environmental risk is even more difficult to imagine, given the underlying (and ecologically desirable) natural variation in environmental risk. The case of equal risk distribution would seem achievable by a randomized collocation of individuals and risks, but even then there would need to be austere restrictions on relocation of either. Ringquist's (2006) conclusion also touches on some of these issues for anthropogenic risk sources.

${ }^{5}$ Most studies use as a dependent variable some measure of an environmental disamenity, $\mathrm{x}$, an element in the vector of other environmental disamenities and amenities, X. Individuals enjoy the multiple aspects of their environmental quality along with a vector of other local public goods, Z. They also possess some income Y. We might define an indirect utility function for the individual as $\mathrm{V}=\mathrm{f}(\mathrm{X}, \mathrm{Y}, \mathrm{Z})$. Comparisons of $\mathrm{x}$ across individuals, or between the observed 
and counterfactual scenarios, may be poor indicators of variations in well-being when numerous processes exist in which individuals can directly or indirectly trade off $\mathrm{X}, \mathrm{Y}$, or $\mathrm{Z}$ for $\mathrm{X}$. Yet, in a sense, it is this restriction to $\mathrm{x}$ (or $\mathrm{X}$ ) that distinguishes EJ from broader "social justice" issues. ${ }^{6}$ Another way to mobilize the EJ movement, it has been suggested, is around the concept of “environmental justice communities.” While definitions may vary, one approach focuses efforts to support or empower these environmental justice communities because they are "at risk" of disproportionate impact - even if their impact is not in fact disproportionate. The EJ communities are typically identified as minority, low-income, or disadvantaged in some other way. This construction of EJ shifts the focus from inequitable environmental impacts to inequitable power or resource distribution. The policy response is to confer special benefits or treatment to EJ communities, not necessarily as compensation for environmental harms, but as a way to "level the playing field" more generally.

${ }^{7}$ Depending on how the impact is measured, achieving the counterfactual of perfect equality seems both hugely impractical and highly inefficient. A policy or system that actually induced uniform environmental quality would wreak havoc on underlying natural variations. It would also ignore economies and diseconomies of scale and place, heterogeneous preferences, and other diverse sorting. The policy or system that could actually yield such a just distribution of environmental quality would be interesting to see elaborated and justified, but this has not yet been done to my knowledge. Schweitzer and Stephenson (2007) also identify this shortcoming in the context of environmental equity and urban sustainability theorists.

${ }^{8}$ Of course, more information can also enhance claims of injustice, such as when the observed distribution appears equitable but is actually the result of unjust or racist policies or systems. 
${ }^{9}$ Table 3 contains logit regression results based on block-group level data from the 2000 Census. Income is median household income (in \$1000s), density is population density, and the "MSAdum” is merely an indicator of whether the unit was in an MSA in 2000. "MSA FE” and “State FE" refer to vectors of dummy variables for each MSA and state, respectively. The N includes all units with complete information, although specific models will drop observations when there is no variance within a particular group (e.g., no NPL sites in a particular MSA). 10 EJ advocates are likely to disagree. Yet it is my contention that equity (procedural fairness and distributional considerations) plays important, even dominant, roles in the making of environmental policies in the U.S.. It is not my contention that the resulting policies, their implementations, or outcomes generally are equitable. Obviously, giving equity a role in policymaking is not a sufficient condition for the resulting policies or outcomes to be equitable. Nonetheless, ample theory and evidence have been offered to support the prominent role of equity and distributional considerations in policymaking generally, in regulatory behavior, and in environmental policy. A review of this literature is beyond the scope of this paper, but readers are referred to start at Gray and Shadbegian (2004), Earnhart (2004), and more generally Keohane et al. (1998).

11 Ideally, they would also pay for enjoying environmental amenities. 